Discussion Laboratory animal workers may have specific $\operatorname{IgE}$ antibodies to either Mus m 1 or mouse epithelium. Diagnostic tests for mouse sensitisation may require testing to both Mus $\mathrm{m}$ 1 and mouse epithelium to ensure we do not miss any sensitised cases. Skin prick tests appear higher rates of false negative than anticipated and are therefore less reliable in clinical practice if used alone.

\section{P54 RESPIRATORY SYMPTOMS, LUNG FUNCTION AND QUALITY OF LIFE IN BRITISH FOUNDRY WORKERS}

${ }^{1} R E$ Wiggans, ${ }^{2} \mathrm{~L}$ Lewis, ${ }^{3} \mathrm{~J}$ Sumner, ${ }^{3} \mathrm{E}$ Robinson, ${ }^{3} \mathrm{~L}$ Bradshaw, ${ }^{3} \mathrm{~A}$ Codling, ${ }^{3} \mathrm{D}$ Fishwick, ${ }^{3} \mathrm{CM}$ Barber. 'Department of Infection and Immunity, University of Sheffield, Sheffield, UK; ${ }^{2}$ Department of Respiratory Medicine, Sheffield Teaching Hospitals, Sheffield, UK; ${ }^{3}$ Centre for Workplace Health, Health and Safety Laboratory, Harpur Hill, Buxton, UK

\subsection{6/thoraxjn-2015-207770.191}

Introduction Foundry work is associated with exposure to potentially harmful substances that may cause occupational asthma (OA).

Aim To record respiratory symptoms, lung function and healthrelated quality of life (HRQoL) in a group of exposed British foundry workers, and investigate their associations and causes.

Method A workplace-based study was conducted, where participants were delivered a researcher-administered questionnaire in order to record individual job exposures, respiratory and general health, and HRQoL (the EQ-5D). Spirometry was performed using a --Ndd Easy on-PC Spirometer according to ATS/ERS guidelines. Fractional exhaled nitric oxide $\left(\mathrm{FE}_{\mathrm{NO}}\right)$ was measured using a NOBreath device to ATS standards.

Results $351(65 \%)$ of a possible 539 workers participated. 350 $(99.7 \%)$ were men, with a mean age of 42.4 (SD 12.5) years. The average length of employment in the foundry industry was 14.8 (SD 12.7) years. Twenty-one (6\%) workers self-reported a diagnosis of current asthma, and six (1.7\%) selfreported COPD.

$139(40 \%)$ participants had at least one respiratory symptom, of which wheeze was the most prevalent $(\mathrm{n}=114,33 \%)$. Onein-five participants reported work-related respiratory symptoms (WRRS) ( $\mathrm{n}=69,20 \%)$, of which work-related cough was the most prevalent $(\mathrm{n}=45,13 \%$; Table 1$)$. Significantly more workers reporting WRRS were ever smokers (chi squared $=5.1, \mathrm{p}=$ $0.02)$.

Abstract P54 Table 1 Demographic data for British foundry workers with and without work-related respiratory symptoms (WRRS)

\begin{tabular}{lll}
\hline & WRRS $(\mathbf{n}=69)$ & No WRRS $(\mathbf{n}=\mathbf{2 8 2})$ \\
\hline Age, years (SD) & $41.1(12.3)$ & $42.7(12.5)$ \\
Length of employment, years (SD) & $15.4(12.3)$ & $14.7(12.8)$ \\
Current smoker, $n$ (\%) & $25(36)$ & $71(25)$ \\
Ever smoker, $n$ (\%) & $48(70)$ & $154(55)^{*}$ \\
Self-reported current asthma, $n$ (\%) & $8(12)$ & $13(5)$ \\
FEV 1 /FVC <0.7, n (\%) & $3(4)$ & $31(11)$ \\
Mean\% predicted FEV 1 (SD) & $98.3(10.5)$ & $98.4(14.1)$ \\
Mean\% predicted FVC (SD) & $103.1(9.8)$ & $103.6(12.8)$ \\
Mean\% predicted PEF (SD) & $106.2(17.1)$ & $108.3(18.2)$ \\
Mean FE $E_{\text {NO }}$ ppb (SD) & $31.1(24.2)$ & $29.9(29.0)$ \\
Mean EQ-5D VAS (SD) & $76.6(15.8)$ & $83.5(11.0)^{* *}$ \\
\hline${ }^{*} \mathrm{p}=<0.05,{ }^{* *} \mathrm{p}=0.001$. & &
\end{tabular}

155 (44\%) workers had a $\mathrm{FE}_{\mathrm{NO}}$ above $25 \mathrm{ppb}$, the suggested ATS cut off for a low probability of eosinophilic airway inflammation. No difference in $\mathrm{FE}_{\mathrm{NO}}$ was found between those with and without WRRS (chi squared for $\mathrm{FE}_{\mathrm{NO}}$ above or below 25 $\mathrm{ppb}=1.50, \mathrm{p}=0.22$ ).

However, WRRS were associated with significantly lower mean scores on the EQ-5D visual analogue scale (VAS; 77 vs 84, $\mathrm{p}=0.001,95 \%$ CI $2.89-11.01)$. In contrast, no difference in VAS was observed between those with and without an obstructive lung defect $\left(\mathrm{FEV}_{1} / \mathrm{FVC}<0.7\right)$, (mean 83 vs $82, \mathrm{p}=0.63$, 95\% CI $-5.48-3.33)$.

Conclusion Work-related respiratory symptoms among foundry workers were common and associated with impaired HRQoL. More work is required to better understand the cause of such symptoms in foundry workers, and their relationship with workplace exposures.

\section{P55 THE OCCUPATIONS ASSOCIATED WITH COPD RISK IN THE LARGE POPULATION-BASED UK BIOBANK COHORT STUDY}

${ }^{1} \mathrm{~S}$ De Matteis, 'D Jarvis, ' $\mathrm{S}$ Hutchings, ${ }^{2} \mathrm{~A}$ Darnton, ${ }^{1} \mathrm{~L}$ Rushton, ${ }^{1} \mathrm{P}$ Cullinan. ${ }^{1} / \mathrm{mperial}$ College London, London, UK; ${ }^{2}$ Health and Safety Executive, Bootle, Merseyside, UK

\subsection{6/thoraxjnl-2015-207770.192}

Introduction and objectives COPD is one of the leading causes of morbidity and mortality worldwide. Exposure to occupational hazards is an important and preventable risk factor. However, the contribution of each occupation to COPD risk in a general population is uncertain. Our aim was to investigate the association of COPD with occupation in a large UK population-based study.

Methods Between 2006 and 2010 the UK Biobank cohort recruited 502,649 subjects aged 40-69 years. COPD cases were defined by spirometry-based $\mathrm{FEV}_{1} / \mathrm{FVC}<\mathrm{LLN}$ according to ATS/ERS guidelines. Individual current occupation was coded using the Standard Occupation Classification (SOC) 2000. Prevalence ratios (PRs) and 95\% confidence intervals (CIs) of COPD for exposure to each SOC-coded job were estimated using a robust Poisson model adjusted for sex, age, study centre and lifetime tobacco smoking.

Results Of the 353 SOC-coded jobs reported by 228,614 current working participants several occupations showed a significantly increased COPD risk. The occupations at highest COPD risk were Seafarers (PR $=2.64 ; 95 \%$ CI:1.59-4.38), Coal mine operatives (PR $=2.30 ; 95 \%$ CI:1.00-5.31), Cleaners (Industrial: PR $=1.96 ; 95 \%$ CI:1.16-3.31 and Domestic: $\mathrm{PR}=1.43 ; 95 \%$ CI:1.28-1.59), Roofers/tilers (PR $=1.86 ; 95 \%$ CI:1.29-2.67), Packers/bottlers/canners/fillers $(\mathrm{PR}=1.60 ; 95 \%$ CI:1.15-2.22), Food, drink and tobacco process operatives $(\mathrm{PR}=1.46 ; 95 \%$ CI:1.11-1.93), Floorers and wall tillers $(\mathrm{PR}=1.41 ; 95 \%$ CI:1.00-2.00), Postal workers/couriers $(\mathrm{PR}=1.35 ; 95 \%$ CI:1.15-1.59), Labourers in building and woodworking trades $(\mathrm{PR}=1.32 ; 95 \%$ CI:1.04-1.68), School mid-day assistants $(\mathrm{PR}=1.32 ; 95 \% \mathrm{CI}: 1.01-1.74)$, and Kitchen/catering assistants $(\mathrm{PR}=1.30 ; 95 \% \mathrm{CI}: 1.10-1.53)$. Associations were similar in analyses restricted to never smokers and to subjects never reporting a doctor's diagnosis of asthma.

Conclusions Selected occupations are associated with increased COPD risk in a large cross-sectional population-based UK study. Further analyses to investigate the underlying occupational hazards are planned. Occupational health surveillance among these occupations should be strengthened. 
P56 CROSS-SECTIONAL STUDY OF PREVALENCE OF SENSITISATION TO MOUSE ALLERGENS IN LABORATORY ANIMAL WORKERS: THE SPIRAL (SAFE PRACTICE IN REDUCING ALLERGY IN LABORATORIES) STUDY

${ }^{1} J \mathrm{R}$ Feary, ${ }^{1} \mathrm{~B}$ Fitzgerald, ${ }^{1} \mathrm{Z}$ Lightfoot, ${ }^{1} \mathrm{~W}$ Banya, ${ }^{2} \mathrm{M}$ Jones, ${ }^{2} \mathrm{P}$ Cullinan. ${ }^{1}$ Royal Brompton and Harefield NHS Foundation Trust, London, UK; ${ }^{2}$ Imperial College, London, UK

\subsection{6/thoraxjnl-2015-207770.193}

Introduction At least 12000 people work with laboratory animals in the UK. Approximately $15 \%$ of exposed employees develop specific IgE sensitisation and 10\% clinical symptoms of occupational rhinitis and asthma due to laboratory animal allergy (LAA). Individually ventilated cages (IVCs) are increasingly replacing conventional open cages (primarily for mice welfare); whilst this can be associated with lower levels of ambient aeroallergen levels no corresponding reduction in incidence of LAA is apparent. The SPIRAL (Safe Practice In Reducing Allergy in
Laboratories) study is a large multi-centred study designed to increase understanding of the complex association between workplace exposure to mouse allergens and development of sensitisation, and to evaluate the risk of working with mice today. Methods A cross-sectional study of animal workers at UK medical research institutions is underway. Primary outcome is a comparison of prevalence of sensitisation to mouse proteins in those working in IVC only and those working in mixed facilities (open cages +/- IVCs). Participants complete a detailed online questionnaire including questions about work tasks and practices. Skin-prick tests to common aeroallergens and various animal proteins are performed and blood samples analysed for serum specific IgE to Mus m 1 (mouse urinary protein) and mouse epithelium. Aeroallergen sampling for particulate matter and Mus m 1 is undertaken concurrently to provide objective exposure measurements (results presented elsewhere).

Results 507 participants have been recruited to date. Analyses were restricted to those with less than 5 years exposure to mice

Abstract P56 Table 1 Characteristic of study participants with up to 5 years exposure to mice according to sensitisation status

\begin{tabular}{|c|c|c|c|}
\hline \multicolumn{2}{|l|}{ Variable } & Not sensitised n (\%) & Sensitised n (\%) \\
\hline & & $n=202$ & $\mathrm{n}=10$ \\
\hline \multicolumn{2}{|c|}{ Age in years (median (range)) } & $26.2(11.8,61.2)$ & $24.9(21.8,27.4)$ \\
\hline \multicolumn{2}{|l|}{ Male } & 79 (31.1) & $4(40.0)$ \\
\hline \multirow[t]{3}{*}{ Smoking status } & Never & $154 / 201(76.6)$ & $6(60.0)$ \\
\hline & Ex & $28 / 201$ (13.9) & 0 \\
\hline & Current & $19 / 201(9.5)$ & $4(40.0)$ \\
\hline \multicolumn{2}{|l|}{ Atopic* } & $56 / 198(28.3)$ & $7 / 10(70.0)$ \\
\hline \multirow[t]{4}{*}{ Older siblings } & 0 & $112 / 201(55.7)$ & $3(30.0)$ \\
\hline & 1 & $72 / 201(35.8)$ & $4(40.0)$ \\
\hline & 2 & $11 / 201(5.5)$ & $1(10.0)$ \\
\hline & $3+$ & $6 / 201(3.0)$ & $2(20.0)$ \\
\hline \multicolumn{2}{|l|}{ Years worked with mice } & $2.12(0,4.98)$ & $2.57(1.10,4.15)$ \\
\hline \multicolumn{2}{|c|}{ No previous occupational exposure to mice } & $142 / 201(70.7)$ & $8(80.0)$ \\
\hline \multirow[t]{6}{*}{ Site } & A & $24 / 24(100)$ & 0 \\
\hline & B & $82 / 90(91.1)$ & $8 / 90(8.9)$ \\
\hline & C & $32 / 32(100)$ & 0 \\
\hline & D & $26 / 27(96.3)$ & $1 / 27(3.7)$ \\
\hline & $\mathrm{E}$ & $27 / 28(96.4)$ & $1 / 28(3.6)$ \\
\hline & $\mathrm{F}$ & $11 / 11(100)$ & 0 \\
\hline \multirow[t]{3}{*}{ Job title } & Technician & $57 / 59(96.6)$ & $2 / 59(3.4)$ \\
\hline & Scientist & $132 / 140(94.3)$ & $8 / 140(5.7)$ \\
\hline & Other & $13 / 13(100)$ & 0 \\
\hline \multirow[t]{2}{*}{ Cage type } & IVC only & $109 / 199(54.8)$ & $4(40.0)$ \\
\hline & Open/mixed & $90 / 199(45.2)$ & $6(60.0)$ \\
\hline \multirow[t]{3}{*}{ Work related symptoms } & Conjunctivitis & $25 / 201(12.4)$ & $5(50.0)$ \\
\hline & Rhinitis & $41 / 201(20.4)$ & $7(70.0)$ \\
\hline & Asthma & $6 / 201(3.0)$ & $3(30.0)$ \\
\hline
\end{tabular}

* saline-adjusted wheal of $\geq 3 \mathrm{~mm}$ to grass, house dust mite or cat on skin prick testing 